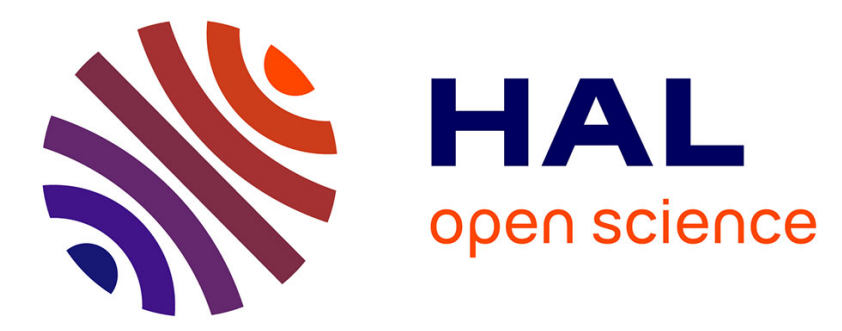

\title{
Ultra high barrier materials for encapsulation of flexible organic electronics
}

S. Logothetidis, A. Laskarakis, D. Georgiou, S. Amberg-Schwab, U. Weber, K. Noller, M. Schmidt, E. Küçükpinar-Niarchos, W. Lohwasser

\section{- To cite this version:}

S. Logothetidis, A. Laskarakis, D. Georgiou, S. Amberg-Schwab, U. Weber, et al.. Ultra high barrier materials for encapsulation of flexible organic electronics. European Physical Journal: Applied Physics, 2010, 51 (3), pp.33203. 10.1051/epjap/2010102 . hal-00618493

\section{HAL Id: hal-00618493 \\ https://hal.science/hal-00618493}

Submitted on 2 Sep 2011

HAL is a multi-disciplinary open access archive for the deposit and dissemination of scientific research documents, whether they are published or not. The documents may come from teaching and research institutions in France or abroad, or from public or private research centers.
L'archive ouverte pluridisciplinaire HAL, est destinée au dépôt et à la diffusion de documents scientifiques de niveau recherche, publiés ou non, émanant des établissements d'enseignement et de recherche français ou étrangers, des laboratoires publics ou privés. 
Ultra high barrier materials for encapsulation of flexible organic electronics

S. Logothetidis ${ }^{1}$, A. Laskarakis ${ }^{1}$, D. Georgiou ${ }^{1}$, S. Amberg-Schwab ${ }^{2}$, U. Weber $^{2}$, K. Noller ${ }^{3}$, M. Schmidt $^{3}$, E. Küçükpinar ${ }^{3}$, W. Lohwasser ${ }^{4}$

1 Aristotle University of Thessaloniki, Department of Physics, Laboratory for Thin Films - Nanosystems and Nanometrology, GR-54124 Thessaloniki, Greece

2 Fraunhofer-Institut für Silicatforschung (ISC), 97082 Würzburg, Germany

3 Fraunhofer-Institut für Verfahrenstechnik und Verpackung (IVV), Freising, Germany

4 Alcan Technology \& Management AG, Neuhausen, Switzerland

\begin{abstract}
The encapsulation of the active layers (organic semiconductors, electrodes, transparent conductive oxides, etc.) of Organic Electronic devices developed onto flexible polymeric substrates is one of the most challenging issues in the rapidly emerging area of Organic Electronics. The importance for the protection of the active layers arises from the fact that these are very sensitive when they are subjected to the atmosphere, since the permeation of the atmosphere's water vapour $\left(\mathrm{H}_{2} \mathrm{O}\right)$ and oxygen $\left(\mathrm{O}_{2}\right)$ gases induces corrosion effects, film delamination and finally, failure of the organic electronic device. In addition, the encapsulation layers contribute to the long-term stability of the whole device enabling its use in outdoor environments (e.g. in the case of flexible photovoltaic cells-OPVs). A promising approach for the encapsulation of flexible organic electronics includes the development of multilayers that consist of hybrid polymer materials and inorganic layers onto flexible polymeric substrates, such as Poly $($ Ethylene Terephthalate) (PET). This approach leads to a significant improvement of the barrier performance of the whole structure, due to the synergetic effect of the confinement of the permeation to the defect zones of the inorganic layer, and the formation of chemical bonds between the hybrid polymer and the inorganic layer. The knowledge of their optical properties and their correlation with their barrier performance are of major importance since it will contribute
\end{abstract} Supprimé : response 
towards the optimization of their functionality. In this work, we provide an overview on the results concerning the use of hybrid polymers as ultra high barrier materials and moreover we discuss on the effect of inclusion of $\mathrm{SiO}_{2}$ nano-particles on their optical properties and barrier performance. organic electronics

Supprimé : functionality

PACS: 78.20.-e, 78.40.Me, 78.66.Qn 


\section{Introduction}

One of the main challenges for the fabrication of flexible organic electronic devices is to achieve a sufficient protection of the active layers of these devices from the penetration of atmospheric gas molecules $\left(\mathrm{O}_{2}\right.$ and $\left.\mathrm{H}_{2} \mathrm{O}\right)$ [1-4] This is an undesired phenomenon because it leads to corrosion of the highly sensitive device active layers (small molecule and polymer organic semiconductors, organic conductors and electrodes, such as transparent conductive oxides, etc.), subsequently limiting the functionality, performance and stability of these layers as well as of the whole device[2,5-7]. Another result of the atmospheric gas molecule permeation is the organic film delamination that also leads to the failure of the organic electronic device[5,6,8].

The commercially supplied polymer films that are used as flexible substrates, such as Poly(Ethylene Terephthalate) (PET) and Poly(Ethylene Naphthalate) (PEN), exhibit permeability values for oxygen transmission rate (OTR) and for water vapour transmission rate (WVTR) of $10^{-1}-10^{2} \mathrm{~cm}^{3} / \mathrm{m}^{2} \mathrm{dbar}$ (OTR), g/m² (WVTR), which are sufficient only for some food packaging applications[1,6,7]. However, the requirements in OTR and WVTR values for flexible organic electronic devices, such as organic light emitting diodes (OLEDs) for display and lighting, flexible photovoltaic cells (OPVs) and flexible circuits and sensors, ask for values lower by another 3 orders of magnitude in the range below than $10^{-5} \mathrm{~cm}^{3} / \mathrm{m}^{2} \mathrm{dbar}$ (OTR) and $\mathrm{g} / \mathrm{m}^{2} \mathrm{~d}$ (WVTR), which cannot be obtained by any of the currently used fabrication processes[2].

Some of the conventional encapsulation solutions involve the use of a metal-can or glass substrate with desiccant. Although these methods are somewhat effective, they add weight, thickness and high cost to the device. Another approach for encapsulation materials is the deposition of inorganic thin films, as $\mathrm{SiO}_{\mathrm{x}}$ and $\mathrm{AlO}_{\mathrm{x}}$ onto the flexible polymeric substrate. This reduces the $\mathrm{O}_{2}$ and $\mathrm{H}_{2} \mathrm{O}$ permeation rates just by two to three orders of magnitude from the permeation rate values of the uncoated plastic substrate[2,9-13]. That is since the barrier response of the inorganic coatings is defined by their lattice disorder that results from the deposition process. This disorder has the form of macroand nano-defects (pinholes and micro-cracks) that are formed during the growth process of the inorganic thin films by physical vapour deposition methods such as sputtering and evaporation. These 
defects provide easy pathways for moisture and oxygen permeation, thus limiting the barrier performance of the inorganic film/polymer substrate system[2,9-13].

On the other hand, hybrid polymers have attracted great interest lately for their use as barrier materials. These are inorganic-organic nano-composites that they can be synthesized by sol-gel processes at relatively low temperatures. The combination of hybrid polymers with inorganic layers can overcome the above drawbacks leading to the leads to a significant improvement of the barrier properties of the whole material structure. This is the result of the synergetic effect of the confinement of the permeation to the defect zones of the inorganic layer, and the formation of chemical bonds between the hybrid polymer and the inorganic layer[9,10,11,13].

In this work, we provide an overview of the effect of the architecture of the encapsulation materials structure on its barrier response as well as on the effect of inclusion of $\mathrm{SiO}_{2}$ nano-particles on their optical properties and functionality. The inclusion of $\mathrm{SiO}_{2}$ nano-particles $\left(\mathrm{SiO}_{2}-\mathrm{NP}\right)$ during the synthesis process of the hybrid polymers is a very promising approach for the increase of the barrier response since it can lead to the enhancement of the inorganic-organic cross-linking and the achievement of a more cohesive bonding network between the organic and inorganic components of the hybrid polymers. The investigation of the optical properties of the hybrid polymer layers by the use of Spectroscopic Ellipsometry (SE) which is a non-destructive technique, can provide significant information on the optical transparency, bonding and electronic structure as well as the thickness of the studied materials.

\section{Experimental Details}

The hybrid polymer materials that are studied in this work are the inorganic-organic ORMOCER $®$ polymers (Trademark of Fraunhofer-Gesellschaft zur Förderung der angewandten Forschung e.V., Germany). These nano-composite materials are characterized by strong covalent or ionic-covalent bonds between the inorganic and organic moieties[13,14]. These materials have been synthesized by the sol-gel process and they combine the key properties of their constituents, such as low processing temperatures, functionalization (polymer-like), flexibility (silicone-like) and high transparency, 
chemical and thermal stability, and hardness[13,14]. The following figure shows a schematic representation of the hybrid polymer[13,14].

A promising approach in order to further improve the barrier properties of the hybrid polymers is the inclusion of silicon dioxide particles $\left(\mathrm{SiO}_{2}-\mathrm{NP}\right)$ of different concentrations and different diameters in the lacquer systems during their synthesis process. This method is one possibility to increase the inorganic network degree of the ORMOCER ${ }^{\circledR}$ based polymers and thus should lead to a reduction of the OTR and WVTR values. All the hybrid barrier materials were deposited by lacquering process (Fraunhofer ISC, IVV, Germany) onto different inorganic layers $\mathrm{SiO}_{\mathrm{x}}$ and $\mathrm{AlO}_{\mathrm{x}}$, which have been deposited onto Poly(Ethylene Terephthalate) (PET) flexible polymeric substrates of thickness $50 \mu \mathrm{m}$. The $\mathrm{SiO}_{\mathrm{x}}$ layers are $120 \mathrm{~nm}$ thick and they were deposited by electron beam evaporation (Alcan Technology \& Management, Switzerland), whereas the $\mathrm{AlO}_{\mathrm{x}}$ layers are $40 \mathrm{~nm}$ thick and they were deposited by magnetron sputtering (Applied Materials, Germany)[15].

The optical properties of the samples were measured by Spectroscopic Ellipsometry (SE) by Aristotle University of Thessaloniki, covering an extended spectral region from the Visible (Vis) to the far UltraViolet (fUV) (1.5-6.5 eV). The Vis-fUV SE measurements were performed by a Phase Modulated Spectroscopic Ellipsometer from Horiba Jobin Yvon covering the energy range 1.5-6.5 eV with steps of $20 \mathrm{meV}$. In addition, all optical measurements were performed with the plane of incidence of light parallel to the stretching direction of the PET substrates. The stretching process during the production of PET results to their macromolecular chain rearrangement, leading to optically anisotropic substrates[16,17]. Therefore, the optical properties of all samples were measured with this method in order to obtain comparable results.

Permeation rates of oxygen and water vapor through the barrier materials were measured with using two types of measurement devices: Standard devices (Mocon/Brugger) by Fraunhofer IVV, Germany, were used for samples of permeation rates down to $0.01 \mathrm{~g} /\left(\mathrm{m}^{2} \mathrm{~d}\right)$ for water vapor and down to 0.05 $\mathrm{cm}^{3} /\left(\mathrm{m}^{2} \mathrm{dbar}\right)$ for oxygen. For samples of even lower permeation rates, newly developed testing devices were used. For measuring very low water vapor permeation rates, a gas chromatic-based ultrabarrier measument device (Fraunhofer IVV, Germany) was applied having a lower detection limit of
Supprimé :

Supprimé : 6

Supprimé : , 18

Supprimé : Also, the $\mathrm{p}$

Supprimé : was

Supprimé : a combination of $\mathrm{s}$ 
$\leq 10^{-5} \mathrm{~cm}^{3} /\left(\mathrm{m}^{2} \mathrm{~d}\right)$. For measuring very low oxygen permeation rates, an opto-chemical based ultra barrier measurement device (from Technical University of Graz, Austria)[16] was applied, having a lower detection limit of $<10^{-5} \mathrm{~cm}^{3} /\left(\mathrm{m}^{2} / \mathrm{dbar}\right)$. The water vapor transmission rates were measured at $23^{\circ} \mathrm{C}, 85 \%$ r.h. and $23^{\circ} \mathrm{C}, 100 \%$ r.h., respectively, whereas the oxygen transmission rates were measured at $23^{\circ} \mathrm{C}, \underline{50} \%$ r.h. and $23^{\circ} \mathrm{C}, 0 \%$ r.h., respectively

\section{Results and Discussion}

Figure 2 shows the concept for the improvement of the barrier performance of the encapsulation material, This consists of a sequence of alternating inorganic (e.g. $\mathrm{SiO}_{\mathrm{x}}$, or $\mathrm{AlO}_{\mathrm{x}}$ ) and hybrid polymer bilayers that are deposited on top of the PET flexible polymeric substrate. This combination of the hybrid polymer and the inorganic layer leads to a significant improvement of the barrier properties of the whole material structure. This can be attributed to the synergetic effect of the confinement of the permeation to the defect zones of the inorganic layer, and the formation of chemical bonds between the hybrid polymer and the inorganic layer. Also, the use of alternating inorganic-hybrid layers provides a tortuous path (synergetic barrier effect): The probability for a atmospheric gas molecule to penetrate the entire multilayer structure is significantly reduced if complex pathshave to be followed, minimizing the overall gas permeation[2,10,13].

Figures 3 and 4 show the effect of the addition of inorganic and hybrid layers onto PET on the improvement of the barrier response (reduction of OTR and WVTR values).

As it can be seen from these figures, the barrier performance of the plain PET substrates is in the order of $\mathrm{OTR} \approx 25 \mathrm{~cm}^{3} / \mathrm{m}^{2} \mathrm{dbar}$ and WVTR $\approx 5 \mathrm{~g} / \mathrm{m}^{2} \mathrm{~d}$. However, the addition of the first inorganic layer improves the barrier performance to $(\mathrm{OTR}, \mathrm{WVTR})=\left(0.367 \mathrm{~cm}^{3} / \mathrm{m}^{2} \mathrm{dbar}, 0.11 \mathrm{~g} / \mathrm{m}^{2} \mathrm{~d}\right)$ and $(1$ $\mathrm{cm}^{3} / \mathrm{m}^{2} \mathrm{dbar}, 0.3 \mathrm{~g} / \mathrm{m}^{2} \mathrm{~d}$ ) for the case of $\mathrm{SiO}_{\mathrm{x}}$ and $\mathrm{AlO}_{\mathrm{x}}$ films, respectively. The deposition of a hybrid polymer onto the PET/inorganic film reduces more the OTR and WVTR values to $(\mathrm{OTR}, \mathrm{WVTR})=$ $\left(0.018 \mathrm{~cm}^{3} / \mathrm{m}^{2} \mathrm{dbar}, 0.009 \mathrm{~g} / \mathrm{m}^{2} \mathrm{~d}\right)$ and $\left(0.1 \mathrm{~cm}^{3} / \mathrm{m}^{2} \mathrm{dbar}, 0.1 \mathrm{~g} / \mathrm{m}^{2} \mathrm{~d}\right)$ for $\mathrm{PET} / \mathrm{SiO}_{\mathrm{x}} / \mathrm{hybrid}$ and $\mathrm{PET} / \mathrm{AlO}_{\mathrm{x}} /$ hybrid, respectively
Supprimé : as well as other methods such as

Supprimé : Sensor (for OTR measurements with detection limit of $<10^{-5} \mathrm{~cm}^{3} / \mathrm{m}^{2} \mathrm{dbar}$ ) and a gas chromatic-based ultra-barrier measument device (for WVTR measurements with

Supprimé : g/

Supprimé : Both types have a measurement range starting at $0.005 \mathrm{~cm}^{3} / \mathrm{m}^{2} \mathrm{~d}$ or $0.005 \mathrm{~g} / \mathrm{m}^{2} \mathrm{~d}$, respectively.

Supprimé : has been

Supprimé : was

Supprimé : conditions

Supprimé : .

Supprimé : response

Supprimé : structure

Supprimé : and $\mathrm{t}$

Supprimé : through a

Supprimé : is significantly reduced

Supprimé : response

Supprimé : 1

Supprimé : response 
Finally, the subsequent deposition of an additional bilayer (inorganic/hybrid polymer) on the top of the above structures, leads to a further improvement of barrier performance towards the values of $($ OTR, WVTR $)=\left(0.00032 \mathrm{~cm}^{3} / \mathrm{m}^{2} \mathrm{dbar}, 0.0019 \mathrm{~g} / \mathrm{m}^{2} \mathrm{~d}\right)$ and $\left(0.0076 \mathrm{~cm}^{3} / \mathrm{m}^{2} \mathrm{dbar}, 0.02 \mathrm{~g} / \mathrm{m}^{2} \mathrm{~d}\right)$ when using $\mathrm{SiO}_{\mathrm{x}}$ and $\mathrm{AlO}_{\mathrm{x}}$ films, respectively in the multilayer PET/inorganic/hybrid polymer/inorganic/hybrid polymer.

At this point it has to be noted that the above results are the best values measured from a series of similar multilayer barrier samples. Also, the inorganic and the hybrid polymer films were deposited sequentially onto the PET substrate by large-scale lacquering and physical vapor deposition techniques using web rolls (roll-to-roll methods). This fact increases the importance of these results since large-scale methods is known to provide difficulties in the achievement of the barrier response of the encapsulation layers, since the use of web rolls and the high rotation web speeds lead to defects in the material structure reducing the barrier performance.

Additional information about the performance of the hybrid polymers can be acquired from the investigation of their optical properties by Spectroscopic Ellipsometry (SE) in the visible to far ultraviolet spectral region. In this region, the pseudo-dielectric function $<\varepsilon(\omega)>=<\varepsilon_{1}(\omega)>+\mathrm{i}<\varepsilon_{2}(\omega)>$ of the material provide information on the films thickness, optical transparency (through the calculation of the energy band gap $\omega_{\mathrm{g}}$ and the maximum absorption energy $\omega_{0}$, which corresponds to the electronic interband transition) $[1 \underline{8,19}]$. In this work, we present the latest results that include the investigation of the optical response of hybrid polymers with embedded $\mathrm{SiO}_{2}$ nanoparticles in their structure, and their correlation with the barrier response. The sizes of the $\mathrm{SiO}_{2}-\mathrm{NP}$ are in the range of $60-100 \mathrm{~nm}$.

For the analysis of the optical response of the hybrid polymer with embedded $\mathrm{SiO}_{2}-\mathrm{NP}$ we assume a composite material that is consisted of an organic part (organic component of the hybrid polymer) and an inorganic part that includes both the inorganic component of the hybrid polymer and the embedded $\mathrm{SiO}_{2}-\mathrm{NP}$. The modeling of the optical response of the hybrid polymer has been performed by the Bruggeman Effective Medium Approximation (BEMA) in order to also calculate the volume fraction of each constituent[1 18,19$]$. The optical response of the inorganic and organic parts have been modeled by the use of the Tauc-Lorenz (TL) oscillator model[19,20]. Figure 5 shows the calculated 
values of the fundamental band gap $\omega_{\mathrm{g}}$ and the maximum absorption energy $\omega_{0}$ plotted against the measured WVTR and OTR values [15]. Although a direct correlation between the optical and the barrier values cannot be easily found, since there are several experimental parameters that affect these properties, it is clear that generally, the lowest (highest) values of the $\omega_{\mathrm{g}}\left(\omega_{0}\right)$ are associated with better barrier responses.

As it can be seen from Fig. 5, the hybrid polymers with the best barrier response are the polymers that include $1 \%$ of $\mathrm{SiO}_{2}$-NP in their structure and they are characterized by values of band gap $\omega_{\mathrm{g}}=5.55$ $\mathrm{eV}$ and maximum absorption energy $\omega_{0}=7.35 \mathrm{eV}$. Also, the barrier response of these hybrid polymers is $\mathrm{OTR}=0.0004 \mathrm{~cm}^{3} / \mathrm{m}^{2} \mathrm{dbar}$ and $\mathrm{WVTR}=0.001 \mathrm{~g} / \mathrm{m}^{2} \mathrm{~d}$.

In addition, the investigation of the refractive index $\mathrm{n}(\omega=0)$ can provide information about the density of the hybrid polymers. The value of $\mathrm{n}(\omega=0)$ can be calculated by the relation $\mathrm{n}^{2}(0)=\varepsilon_{1}(0)[1 \underline{8,1} \underline{\underline{v}}$. The value of $\varepsilon_{1}(0)$ can be determined by extrapolating the dielectric function spectra below the lower limit of the experimental spectral range using the corresponding best-fit parameters from the analysis of the $<\varepsilon(\omega)>$ using the TL model, as described above.

The dependence of the calculated refractive index $\mathrm{n}(\omega=0)$ with the content of the $\mathrm{SiO}_{2}-\mathrm{NP}$ in the hybrid polymers can be seen in Fig. 6. From this figure it is clear that the increase of the amount of $\mathrm{SiO}_{2}-\mathrm{NP}$ in the hybrid polymers leads to a reduction of the refractive index $\mathrm{n}(\omega=0)$ values that can be correlated to a reduction of the films density. Taking into consideration the measured barrier response of these materials (see Fig. 5), it leads to the conclusion that the hybrid polymers with lower refractive index (that can be correlated to lower density) are characterized by higher gas molecule permeation values (poorer barrier performance) than the hybrid polymers with higher refractive index values (that can be correlated to higher density).

Another approach for the production of ultra high barrier material structures for the encapsulation of flexible organic electronic devices is the formation of a pouch material structure (Alcan Technology and Management, Neuhausen, Switzerland). This consists of an encapsulated device using the above studied hybrid polymers, which is sealed in a packaging pouch structure. The top layer of this structure consists of a scavenger layer, whereas the bottom layer is made from the above mentioned trans-
Supprimé :, 20

Supprimé : response 
parent hybrid polymer material. The barrier performance of this pouch is estimated to be in the order of $10^{-4}$ (for both OTR and WVTR) and its implementation for the encapsulation of the sensitive active organic electronics layers will allow the increase of their lifetime.

\section{Conclusions}

In this work, we have described the latest advances on the development of hybrid ultra high barrier materials for the encapsulation of flexible organic electronic devices. The subsequent deposition of inorganic/hybrid polymer bilayers on the top of the flexible PET substrate provides a significant improvement of the barrier performance, Moreover, the inclusion of inorganic $\mathrm{SiO}_{2}$ nano-particles with low concentration $(\sim 1 \%)$ in the hybrid polymer structure also improves the barrier properties. However, although the inclusion of $\mathrm{SiO}_{2}$-NP in the hybrid materials is originally intended to provide a more cohesive organic-inorganic network, it has been shown that the increase of the $\mathrm{SiO}_{2}-\mathrm{NP}$ content results to the reduction of the materials refractive index (lower density). This has been justified by representative barrier measurements that have shown that the materials with higher amount of $\mathrm{SiO}_{2}$ NP have poorer barrier performance,

Supprimé : response

\section{Acknowledegments}

The authors would like to thank G. Steiniger and P. Sauer from Applied Materials for the $\mathrm{AlO}_{\mathrm{x}} / \mathrm{PET}$ samples, as well as Graz University of Technology, Austria for their support in the barrier results. This work has been supported by the EC STREP Project FLEXONICS Contract No. NMP3-CT2005-013883. 


\section{References}

[1] G. Dennler, L. C., H. Neugebauer, N. Sariciftci, A. Labouret, Journal of Materials Research 20 (2005) 3224-3233.

[2] S. Logothetidis, A. Laskarakis, European Physical Journal Applied Physics 46 (2009) 12502.

[3] S. Logothetidis, Rev. Adv. Mater. Sci. 10 (2005) 387.

[4] G. Dennler, C. Lungenschmied, H. Neugebauer, N. Sariciftci, M. Latrèche, G. Czeremuszkin, M. Wertheimer, Thin Solid Films 511-512 (2006) 349-353.

[5] M. Yanaka, B. Henry, A. Roberts, C. Grovenor, G. Briggs, A. Sutton, T. Miyamoto, Y. Tsukahara, N. Takeda, R. Chater, Thin Solid Films 397 (2001) 176.

[6] P. Roberts, M. Henry, P. Sutton, M. Grovenor, D. Briggs, T. Miyamoto, M. Kano, M. Yanaka, Journal of Membrane Science 208 (2002) 75-88.

[7] D. Georgiou, A. Laskarakis, S. Logothetidis, S. Amberg-Schwab, U. Weber, M. Schmidt, K. Noller, Applied Surface Science 255 (2009) 8023-8029.

[8] R. Houbertz, G. Domann, C. Cronauer, A. Schmitt, H. Martin, U. Park, L. Frohlich, R. Buestrich, M. Popall, U. Streppel, P. Dannberg, C. Wachter, A. Brauer, Thin Solid Films 442 (2003) 194200.

[9] C. Charton, N. Schiller, M. Fahland, A. Holländer, A. Wedel, K. Noller, Thin Solid Films 502 (2006) 99-103.

[10] S. Amberg-Schwab, H. Katschorek, U. Weber, M. Hoffmann, A. Burger, Journal of Sol-Gel Science And Technology 19 (2000) 125-129.

[11]S. Amberg-Schwab, U. Weber, A. Burger, S. Nique, R. Xalter, Monatshefte Für Chemie 137 (2006) 657-666.

[12] S. Hedenqvist, S. Johansson, Surface and Coatings Technology 172 (2003) 7-12.

Supprimé : And

[13]K. Haas, S. Amberg-Schwab, K. Rose, G. Schottner, Surface \& Coatings Technology 111 (1999) $72-79$.

[14] K. Haas, H. Wolter, Current Opinion in Solid State \& Materials Science 4 (2000) 571-580.

[1,5]_ EC STREP Project FLEXONICS Contract No. NMP3-CT-2005-013883. (n.d.). 
[16] A. Laskarakis, D. Georgiou, S. Logothetidis, S. Amberg-Schwab, U. Weber, Materials Chemistry and Physics 115 (2009) 269-274.

[17]A. Laskarakis, S. Logothetidis, Journal of Applied Physics 101 (2007) 053503.

Supprimé : 8

[1] ] R. Azzam, N. Bashara, Ellipsometry and Polarized Light, North-Holland, Amsterdam, 1977.

[19] H. Tompkins, E. Irene, Handbook of Ellipsometry, William Andrew Publishing, Norwich, NY, 2005.

[20] G. Jellison, F. Modine, Appl. Phys. Lett. 69 (1996) 371.

Supprimé : 


\section{FIGURE CAPTIONS}

Fig. 1. Schematic representation of the structural elements of a hybrid polymer[13,14].

Supprimé :, 15

Fig. 2. Alternating inorganic and hybrid polymer layers deposited onto a flexible polymeric substrate.

Fig. 3. The measured $\mathrm{O}_{2}$ transmission rate (OTR) of the various combinations of barrier materials, starting from the plain PET substrate to the more complex two bilayer structure (PET/inorganic/hybrid/inorganic/hybrid).

Fig. 4. The measured $\mathrm{H}_{2} \mathrm{O}$ transmission rate (WVTR) of the various combinations of barrier materials, starting from the plain PET substrate to the more complex two bi-layer structure (PET/inorganic/hybrid/inorganic/hybrid).

Fig. 5. Dependence of the calculated fundamental gap $\omega_{\mathrm{g}}$ and Penn gap $\omega_{0}$ with the measured OTR and WVTR values of representative hybrid polymers with embedded $\mathrm{SiO}_{2}-\mathrm{NP}[1,5]$.

Fig. 6. Calculated refractive index $n(\omega=0 \mathrm{eV})$ from the measured $<\varepsilon(\omega)>$ of the hybrid polymers with various contents of embedded $\mathrm{SiO}_{2}$ nanoparticles. 


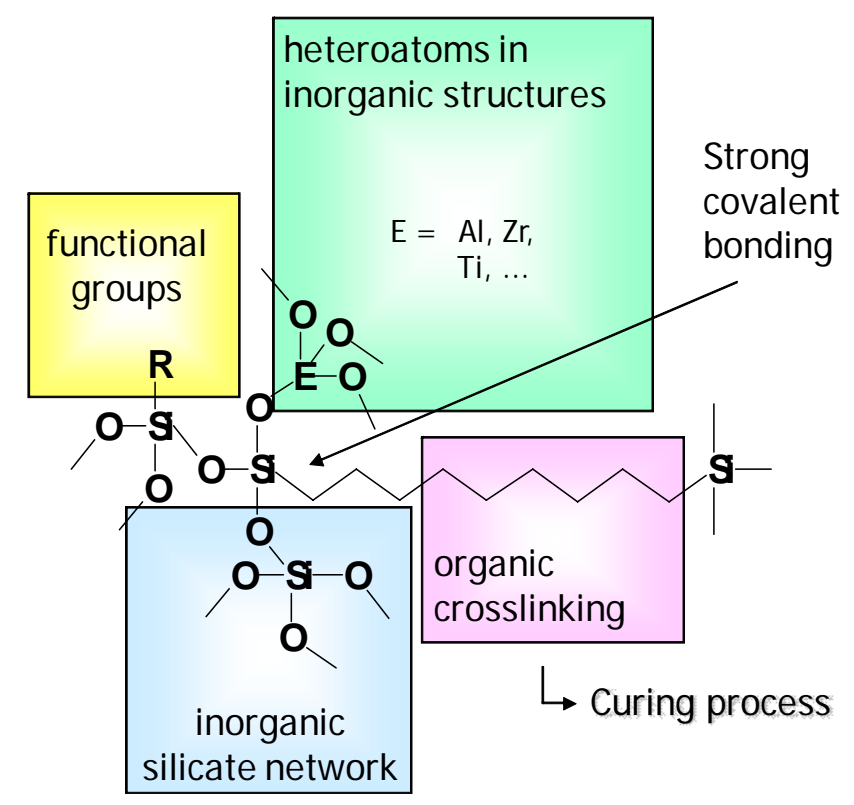

Fig 1. 


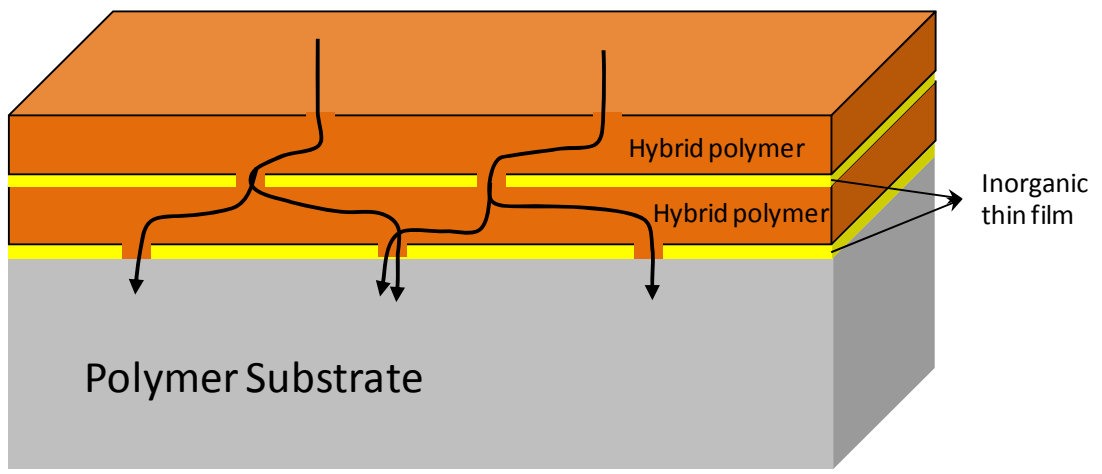

Fig 2. 


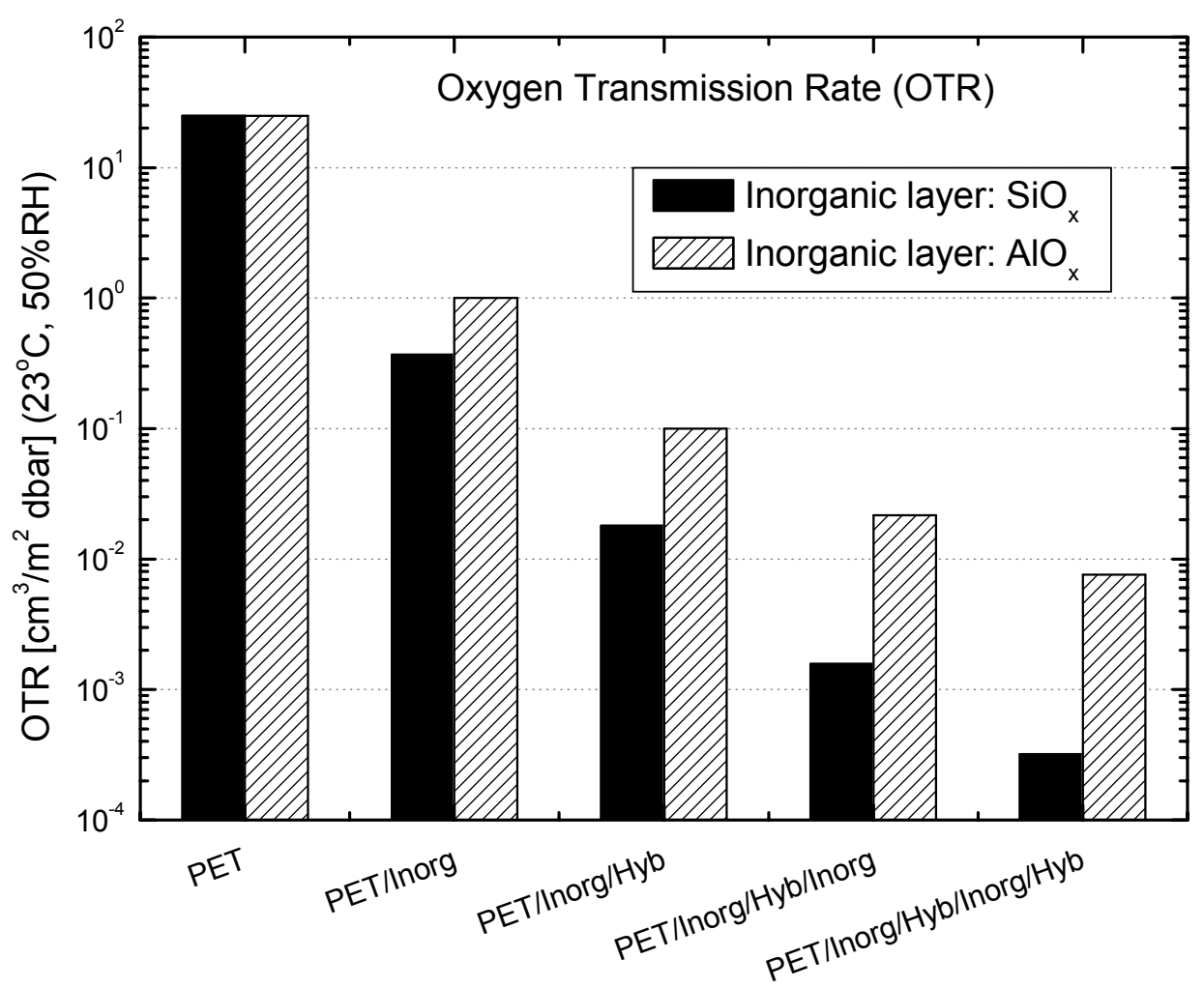

Encapsulation Layer Structure

Fig 3. 


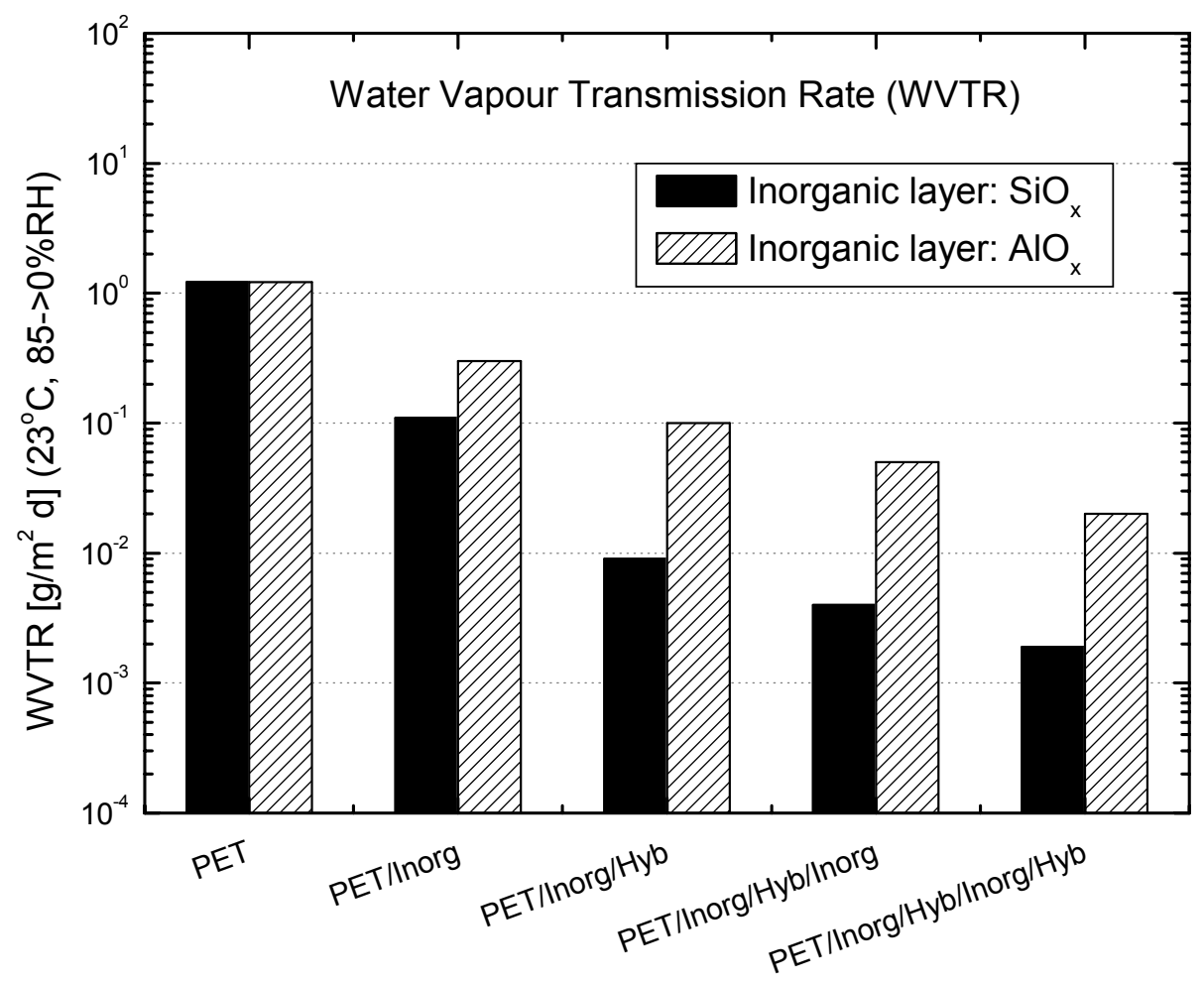

Encapsulation Layer Structure

Fig. 4. 


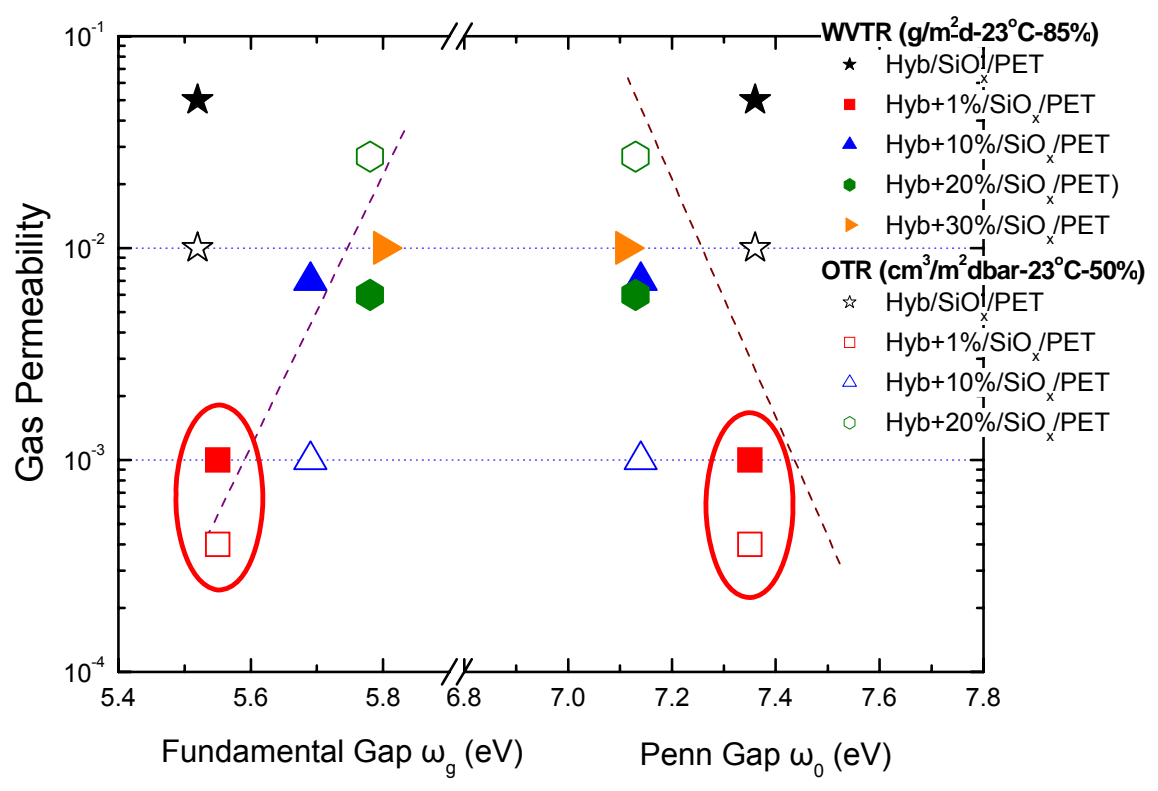

Fig. 5. 


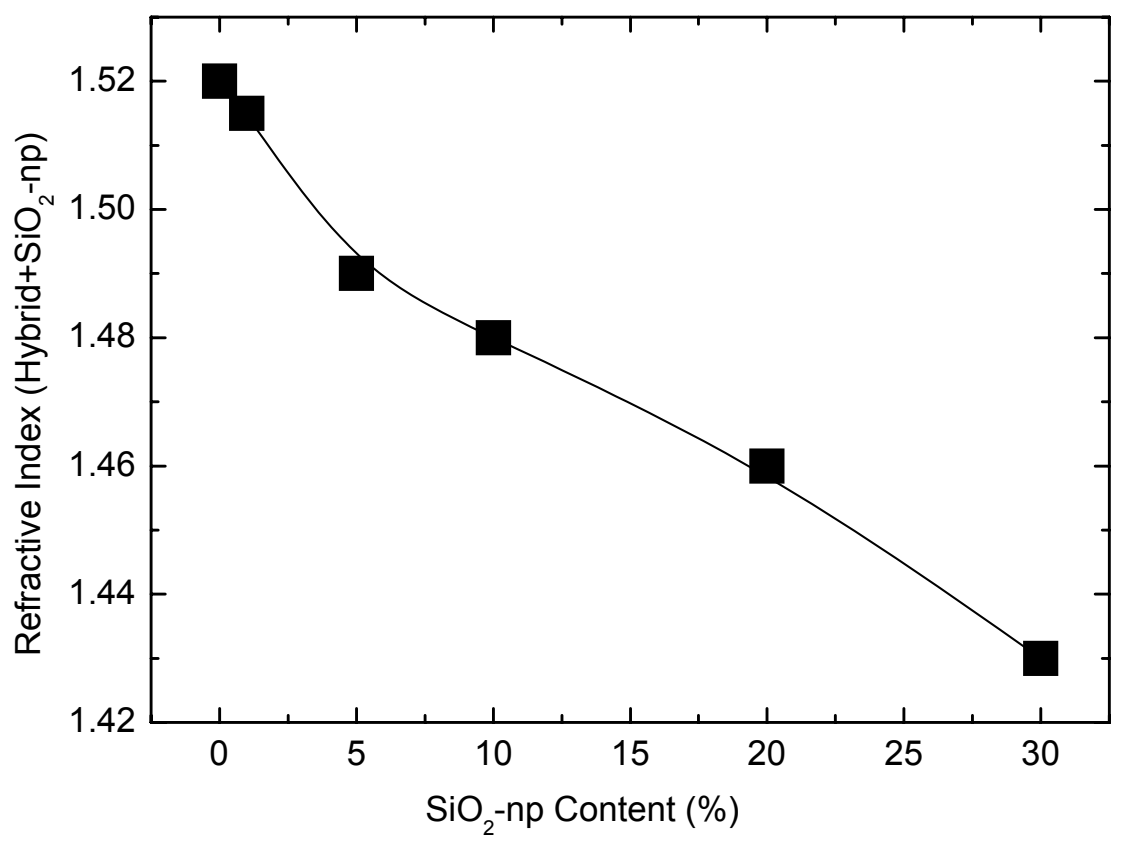

Fig. 6. 